\title{
Gambaran Kualitas Hidup Anak Dengan Kanker Di Wilayah Malang, Indonesia
}

\author{
The Quality of Life Children's With Cancer In Malang Area, Indonesia \\ Feriana Ira Handian ${ }^{1)}$, Lilla Maria ${ }^{2)}$ \\ ${ }^{1}$ Departemen Keperawatan Anak, STIKES Maharani, Malang \\ Email: ferianaazar@gmail.com \\ ${ }^{2}$ Departemen Keperawatan Anak, STIKES Maharani, Malang \\ Email: lilla_mk@yahoo.com
}

\begin{abstract}
ABSTRAK
Pendahuluan: Kanker merupakan salah satu penyakit kronis dapat menimbulkan banyak permasalahan salah satunya adalah menurunnya kualitas hidup. Tujuan dalam penelitian ini adalah untuk menggambarkan kualitas hidup anak dengan kanker di wilayah Malang Raya. Metode: Penelitian deskriptif, sampel penelitian kuantitatif dengan 32 responden orangtua anak kanker. Kualitas hidup diukur dengan PedsQoL Cancer Module 3.0 berdasar laporan orangtua. Analisis data dilakukan menggunakan nilai mean. Hasil: Dari hasil penelitian didapatkan hasil $68,8 \%$ anak dengan kanker mempunyai kualitas hidup yang baik dengan nilai mean $>1,72$, dengan nilai kualitas hidup tertinggi anak dalam adaptasi terhadap tindakan yang menimbulkan kecemasan dan paling sedikit pada munculnya mual muntah. Diskusi/Pembahasan: Peran serta orang tua dan tim kesehatan dalam memberikan dukungan kepada anak akan membuat anak mampu menjalani segala proses pengobatan yang dilakukan sehingga akan meningkatkan kualitas hidup anak dengan kanker.
\end{abstract}

Kata kunci : Kualitas hidup, anak, kanker

\begin{abstract}
Introduction: Cancer is chronic disease that can cause many problems, one of them is decrease in quality of life. The purpose of this study was to see how the quality of life of children with cancer in Malang area, Indonesia. Method: Quantitative research sample with 32 respondents. Quality of life is measured by PedsQoL Cancer Module 3.0 based on parental reports. Data analysis performed using mean value. Results: The results of the study showed that $68.8 \%$ of children with cancer had a good quality of life with a mean value of $>1.72$, with the highest quality of life of children in adaptation to actions that cause anxiety and at least the nausea and vomiting appearance. Discussion/Conslussion: The participation of parents and health team in providing support to children will make children able to undergo all treatment processes carried out so that it will improve the quality of life of children with cancer.
\end{abstract}

Keyword : Quality of life, children, cancer 


\section{PENDAHULUAN}

Kanker merupakan salah satu penyakit kronis dapat menimbulkan banyak permasalahan salah satunya adalah menurunnya kualitas hidup. Anak yang menderita Kanker yang memerlukan pengobatan dan perawatan yang terus menerus dan berkelanjutan. Pengobatan yang dilakukan salah satunya adalah dengan melakukan kemoterapi yang memerlukan waktu berulang kali dan berkelanjutan pada anak. Pengobatan tersebut tentunya memiliki efek terapeutik dan juga menyebabkan berbagai efek samping. Efek samping dari pengobatan pada anak kanker ini dapat berdampak terhadap kualitas hidup anak, meliputi fungsi fisik, emosi, sosial, psikologis dan kognitif. Pada tahun 2012, ditemukan 14,1 juta kasus kanker baru, dengan 8,2 juta kematian akibat kanker dan 32,6 juta orang hidup dengan kanker di seluruh dunia (Globocan, 2012). International Agency for Research on Cancer (IARC) mengungkapkan bahwa anak di dunia yang menderita kanker adalah sekitar 250.000 (Cutland, 2011). Sampai saat ini, kondisi kualitas hidup pada anak kanker di Indonesia masih bervariasi dan menampilkan data yang belum mencukupi. Tujuan dalam penelitian ini adalah untuk menggambarkan kualitas hidup anak dengan kanker di wilayah Malang Raya yang tergabung dalam Komunitas Sahabat Anak Kanker Malang.

\section{METODE}

Sampel penelitian kuantitatif dengan 32 responden yang merupakan orangtua anak kanker selama periode bulan Maret-April 2018 di Kota/Kabupaten Malang, Blitar, Batu dan Pasuruan. Kualitas hidup pada anak diukur dengan menggunakan instrumen PedsQoL Cancer Module 3.0 berdasarkan laporan orangtua berdasarkan laporan orangtua. Analisis data dilakukan menggunakan nilai mean.

\section{HASIL}

1. Karakteristik diagnosis anak dengan kanker

Dari hasil penelitian yang sudah dilakukan didapatkan data bahwa sebagian besar anak memiliki diagnosis ALL sebesar $43,8 \%$ atau sebanyak 14 orang anak, dan yang jarang ditemukan adalah glioma, retinoblastoma dan NHL sebanyak 1 orang atau 3,1\% (gambar 1).

Karakteristik Diagnosis Anak

- Jumlah $\quad \%$

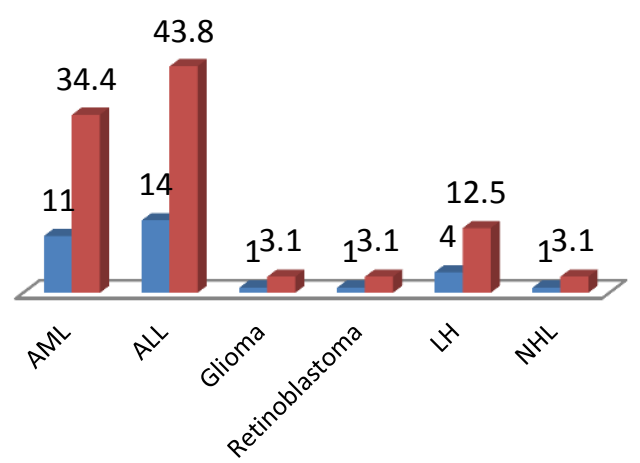

Gambar 1. Karakteristik diagnosis kanker pada anak

2. Penilaian Domain Kualitas Hidup Anak Kanker

Berdasarkan hasil penelitian untuk peniaian domain kualitas hidup pada anak kanker didapatkan hasil bahwa 22 orang atau $68,8 \%$ anak mengalami ketakutan yang tidak bisa dijelaskan penyebabnya dan yang terkecil adalah nausea dan prosedur ansietas sebanyak 9 orang atau $28,1 \%$ (gambar.2) 
Penilaian Domain Kualitas Hidup

Anak Kanker

- Jumlah $\quad \%$

68.8
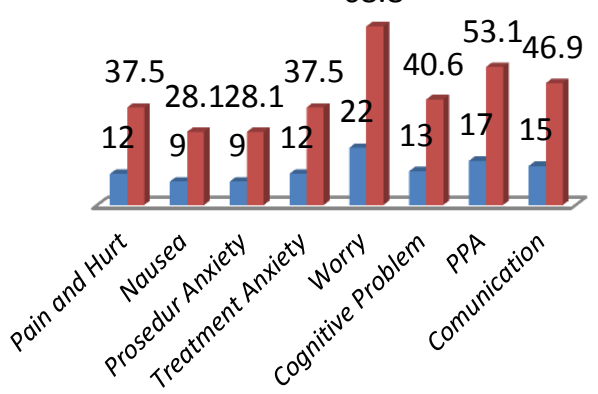

Gambar 2. Penilaian domain kualitas hidup.

3. Gambaran Kualitas Hidup Anak Kanker

Kualitas hidup anak kanker pada penelitian ini ditemukan data bahwa sebagian besar anak mempunyai kualitas hidup yang baik sebesar $65,6 \%$ atau sebanyak 21 orang anak, dan sisanya mempunyai kualitas hidup yang buruk sebanyak 11 anak atau 34,4\% (gambar 3).

Kualitas Hidup Anak Kanker

Baik Buruk

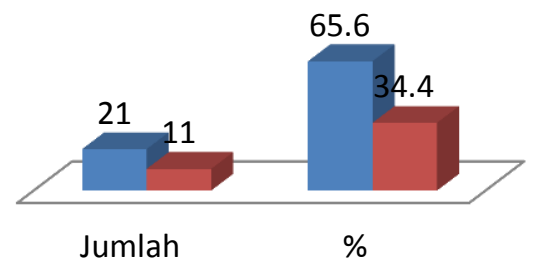

Gambar 3. Penilaian kualitas hidup

\section{PEMBAHASAN}

Kanker merupakan salah satu penyakit kronis yang dapat menimbulkan banyak permasalahan terutama bila hal itu terjadi pada anak yang masih dalam fase tumbuh dan berkembang, salah satu permasalahan yang akan muncul adalah perubahan kualitas hidup.
Pada umumnya protokol kemoterapi melibatkan unsur glukokortikoid mempunyai efek samping antara lain perubahan mood dan perilaku, masalah konsentrasi, gangguan tidur, peningkatan selera makan serta peningkatan nyeri. Dalam waktu jangka panjang, keluhan yang muncul pada anak akan berhubungan dengan kualitas hidupnya. Kemungkinan perasaan cemas anak yang muncul dominan dalam penelitian ini melibatkan berbagai macam stressor, baik yang berasal dari individu maupun dari faktor eksternal yang ditemui oleh anak saat berinteraksi dengan sesama penderita maupun saat pengobatan di rumah sakit (Handian, Fitria, \& Falah, 2017). Pada anak dengan kanker orang tua yang mampu bertahan pada tahap akhir kehidupan anak adalah yang mampu melakukan penundaan kesedihan, menikmati ekspresi kebahagiaan sang anak, memperhatikan identitas anak meskipun ada masalah fisik serta berusaha mendampingi (Kars, Grypdonck, \& Delden, 2011)

Kualitas hidup anak kanker yang baik menurut hasil penelitian yang sudah dilakukan didapatkan hasil bahwa anak terkadang atau hampir tidak pernah merasakan nyeri, mual maupun ketakutan baik terhadap prosedur tindakan yang menyebabkan kecemasan dan prosedur pengobatan serta persepsi terhadap diri mereka juga baik. Mereka mampu mengomunikasikan apa yang mereka rasakan baik kepada orang tua maupun tim tenaga kesehatan hal ini tentunya sesuai dengan penelitian action participatory research yang dilakukan di Inggris yang melibatkan anak dengan kanker dan orangtua, anak menyatakan merasa tidak senang ketika orangtua dan petugas kesehatan melakukan interaksi dan komunikasi tentang penyakit tanpa melibatkan mereka (Gibson et al., 2010).

Dengan melibatkan anak selama proses pengobatan dan komunikasi yang baik antara anak, orang tua dan petugas kesehatan diharapkan akan meningkat kualitas 
pengobatan anak yang nantinya akan berimbas pada peningkatan kualitas hidup anak dengan kanker. Hal tersebut tentunya sejalan dengan penelitian yang dilakukan oleh Heath et al (2012), yang mengungkapkan bahwa komunikasi yang baik, menyenangkan dan terbuka yang diberikan oleh tenaga kesehatan kepada keluarga dapat membantu keluarga untuk memberikan perawatan holistik yang terbaik.

Sedangkan untuk anak dengan kualitas hidup yang buruk sesuai dengan hasil penelitian terbanyak pada perasaan ketakutan yang sering atau bahkan hampir selalu dirasakan oleh anak dan keadaan fisik yang dirasakan oleh anak akibat prosedur pengobatan. Hasil penelitian ini sejalan dengan penelitian yang dilakukan oleh Nurhidayah (2016) bahwa anak kanker merasakan kekhawatiran tentang pengobatan (Nurhidayah, Hendrawati, Mediani, \& Adistie, 2016), akan tetapi dalam penelitian ini tidak ditemui penurunan skor pada kemampuan sekolah dikarenakan pengunaan instrument yang berbeda. Terkait dengan keluhan yang dirasakan, hal ini sesuai dengan penelitian Sitaresmi et al (2009) bahwa efek samping yang paling banyak dilaporkan oleh orangtua akibat kemoterapi adalah perubahan perilaku.

Berdasarkan penelitian ini, kualitas hidup yang memiliki skor lebih rendah dialami oleh anak dengan diagnosis retinoblastoma, limphoma hodgkin (LH), Glioma, Acute Myeloblastic Leukemia (AML). Secara anatomis, sel-sel kanker yang menyerang pada anak dengan retinoblastoma dan glioma melibatkan susunan syaraf pusat dan dalam perjalanannya memiliki kecenderungan adanya penyerta serangan kejang apabila anak mengalami peningkatan tekanan intrakranial. Pada anak dengan glioma, kemoterapi yang dilakukan oleh anak bukan satu-satunya tindakan yang dapat mengatasi kejang, terapi lain yang disarankan adalah dengan terapi central nervous system (CNS) (Tomlinson \& Kline, 2010) .
Pada anak dengan AML, pada penelitian ini memiliki skor rendah terjadi pada anak dengan AML M4, dengan jumlah sel blast mencapai $>30 \%$ pada pemeriksaan morfologis sel darah putih. Kondisi inilah yang mungkin mengakibatkan penurunan nilai kualitas hidup anak dengan deskripsi pada rasa nyeri yang lebih sering dirasakan pada beberapa bagian tubuh, ketakutan terhadap prosedur dan kesulitan menjelaskan penyakitnya kepada orang lain.

Pada kondisi anak dengan LH, situasi yang dihadapi berdasarkan hasil penelitian ini adalah perasaan anak yang menjadi malu dengan adanya pembengkakan yang dialami, misalnya di wajah atau organ lain yang terlihat oleh teman. Pada satu orangtua dengan anak limfoma non Hodgkin (LNH), perasaan malu atau merasa kurang tampan dialami oleh anak saat proses metastase terjadi pada indera yang lainnya, misalnya pada saat menurunnya fungsi penglihatan akibat paralisis. Keadaan ini menjadi stressor bagi anak sehingga mereka mengalami gangguan saat berinteraksi dengan teman sebaya.

Mengingat lamanya pengobatan yang dilakukan maka motivasi orang tua dan tenaga kesehatan sangat diperlukan dalam peningkatan kualitas hidup anak sehingga mereka bisa menyelesaikan semua pengobatan yang sudah direncanakan dan mempertahankan kualitas hidup mereka. Anak dengan kanker harus selalu dalam pemantauan meskipun sudah selesai rangkaian pengobatannya sampai anak berumur 18 tahun. Dalam hal ini sangat diperlukan adanya dukungan keluarga yang solid dan terus menerus kepada anak agar mampu bertahan dan berusaha untuk mengatasi segala yang dirasakan oleh anak. Pandangan ini sejalan dengan teori resiliensi stres McCubbin\&McCubbin (1988), keluarga adalah sebuah sistem yang dibentuk oleh individu dalam keluarga sebagai komponennya dan pusat dari sistem adalah keluarga itu sendiri (VanBreda, 2001). 


\section{KESIMPULAN DAN SARAN}

\section{KESIMPULAN}

Kualitas hidup anak kanker pada penelitian ini bervariasi sebagian besar baik dan masih ada yang buruk. Kemungkinan faktor yang berhubungan adalah tingkat prognosis penyakit dan kondisi metastasis sel kanker.

\section{SARAN}

Perlu peran serta yang baik dari keluarga dan tim kesehatan untuk memberikan dukungan kepada anak agar anak mempunyai harapan untuk sembuh yang akan berimbas kepada kualitas hidup anak yang lebih baik lagi, perlu penelitian lanjutan tentang faktor-faktor yang mempengaruhi kualitas hidup anak dengan kanker.

\section{KEPUSTAKAAN}

Cutland. (2011). Your Group is Not Alone:Handbook for New Childhood Cancer Foundation,especially in Developing Countries.

Gibson, F., Aldiss, S., Horstman, M., Kumpunen, S., \& Richardson, A. (2010). Children and Young People' s Experiences of Cancer Care: A Qualitative Research Study Using Participatory Methods. International Journal of Nursing Studies, 47(11), 1397-1407.

http://doi.org/10.1016/j.ijnurstu.2010.03 .019

Globocan. (2012). Globocan 2012:Estimated Cancer Incidence,Mortality and Prevalence World Wide in 2012. Retrieved from http://globocan.iarc.fr/Default.aspx
Handian, F. I., Fitria, Y., \& Falah, M. R. (2017). Mendukung Kepatuhan Pengobatan dengan Berbagi Kebahagiaan dan Menjadi Sahabat: Studi Kasus di Komunitas Sahabat Anak Kanker Malang,Indonesia. The Indonesian Journal Of Health Science, 8(2), 165-170. Retrieved from http://jurnal.unmuhjember.ac.id/index.p hp/TIJHS/article/view/870/692

Kars, M. C., Grypdonck, M. H. F., \& Delden, J. J. M. Van. (2011). Being a Parent of a Child With Cancer Throughout the End-of-Life Course. Oncology Nursing Forum, 38(4), E260-271.

Nurhidayah, I., Hendrawati, S., Mediani, H. S., \& Adistie, F. (2016). Quality of Life of Children Living with Cancer. Jurnal Keperawatan Padjajaran, 4(April 2016), 45-59.

Tomlinson, D., \& Kline, N. E. (Eds.). (2010). Pediatric Oncology Nursing:Advanced Clinical Handbook (2nd Ed). New York: Springer.

VanBreda, A. (2001). A Resiliency Theory: Literature Review. Military Psycological Institute South Africa, South African.

Sitaresmi, M. N., Mostert, S., Schook, R. M., Sutaryo, \& Veerman, A. J. P. (2010). Treatment Refusal and Abandonment in Childhood Acute Lymphoblastic Leukemia in Indonesia: an Analysis of Causes and Consequences. PsychoOncology, 19(361), 361-367

VanBreda, A. (2001). A Resiliency Theory: Literature Review. Military Psycological Institute South Africa, South African 